ARTICLE

https://doi.org/10.1038/s41467-019-11643-6

\title{
Significant contribution of metastable particulate organic matter to natural formation of silver nanoparticles in soils
}

Ying-Nan Huang ${ }^{1,2}$, Ting-Ting Qian ${ }^{1,4}$, Fei Dang ${ }^{1,2}$, Yong-Guang Yin ${ }^{3}$, Min Li $^{1,2}$ \& Dong-Mei Zhou (D) 1,2

Particulate organic matter (POM) is distributed worldwide in high abundance. Although insoluble, it could serve as a redox mediator for microbial reductive dehalogenation and mineral transformation. Quantitative information on the role of POM in the natural occurrence of silver nanoparticles (AgNPs) is lacking, but is needed to re-evaluate the sources of AgNPs in soils, which are commonly considered to derive from anthropogenic inputs. Here we demonstrate that POM reduces silver ions to AgNPs under solar irradiation, by producing superoxide radicals from phenol-like groups. The contribution of POM to the naturally occurring AgNPs is estimated to be $11-31 \%$. By providing fresh insight into the sources of AgNPs in soils, our study facilitates unbiased assessments of the fate and impacts of anthropogenic AgNPs. Moreover, the reducing role of POM is likely widespread within surface environments and is expected to significantly influence the biogeochemical cycling of $\mathrm{Ag}$ and other contaminants that are reactive towards phenol-like groups.

\footnotetext{
${ }^{1}$ Key Laboratory of Soil Environment and Pollution Remediation, Institute of Soil Science, Chinese Academy of Sciences, 210008 Nanjing, People's Republic of China. ${ }^{2}$ University of Chinese Academy of Sciences, 100049 Beijing, People's Republic of China. ${ }^{3}$ State Key Laboratory of Environmental Chemistry and Ecotoxicology, Research Center for Eco-Environmental Sciences, Chinese Academy of Sciences, 100085 Beijing, People's Republic of China. ${ }^{4}$ Present address: Advanced Environmental Biotechnology Centre, Nanyang Environment and Water Research Institute, Nanyang Technological University, 1 Cleantech Loop, Singapore 637141, Singapore. Correspondence and requests for materials should be addressed to F.D. (email: fdang@issas.ac.cn) or to D.-M.Z. (email: dmzhou@issas.ac.cn)
} 
S oil organic matter, a continuum of progressively decomposing organic compounds, plays an important role in the global carbon budget and nutrient retention ${ }^{1,2}$. Most organic matter in soils is in particulate, known as humin, rather than in a dissolved form ${ }^{3}$. Particulate organic matter (POM) has been identified as a metastable phase $e^{4,5}$, i.e., insoluble but could be chemically active in extracellular electron transfer in microbial reduction of, for example, iron oxide and pentachlorophenol dechlorination $^{6-8}$. However, the effects of POM on the geochemical transformation of trace metals are unclear. Considering that POM is distributed worldwide in high abundance ${ }^{3,5}$, typically comprising $>50 \%$ of soil organic matter in mineral soils and $>70 \%$ of that in lithified sediments ${ }^{4}$, identifying the mechanisms underlying its reactivity will provide new insight into its role in the cycling of numerous trace metals within surface environments.

One of the current major concerns is the unintentional release of anthropogenic silver nanoparticles (AgNPs), which have unique properties, leading to specific benefits and impacts ${ }^{9}$. Recently a significant fraction of AgNPs has been directly detected in ionic silver-contaminated soils, where anthropogenic input (e.g., anthropogenic AgNPs in industrial, medical, and consumer products) was unlikely ${ }^{10-13}$. Therefore, this work aimed to reveal the formation processes and mechanisms of naturally occurring AgNPs in soils. Although silver ions $\left(\mathrm{Ag}^{+}\right)$ can be readily reduced to AgNPs by microorganisms and their associated extracellular polymeric substances ${ }^{14-16}$, the mechanism allowing the abiotic reduction of $\mathrm{Ag}^{+}$is largely unknown. Studies on the role of organic matter in natural formation of AgNPs have focused on dissolved organic matter (DOM) in lakes and rivers ${ }^{17-20}$, but an extrapolation of the results to POM is difficult due to the distinct differences in the physical and the chemical properties of these two media ${ }^{4,5,21}$. Therefore, DOM fails to explain the natural formation of AgNPs in soils ${ }^{17,19}$. The higher relative abundance of POM than DOM and the redox ability of POM lead us to hypothesize that POM participates in reducing $\mathrm{Ag}^{+}$to AgNPs at the soil surface. A demonstration of this interaction would be of considerable importance, as it would enable researchers to re-evaluate the presence and source of AgNPs in terrestrial environment, and thus to conduct unbiased assessments of fate and impacts of anthropogenic AgNPs.

In this work, we identify a clear role for POM in the natural formation of AgNPs, both in the sand matrix and heterogeneous suspensions. The use of this simplified system has significant advantages over natural samples, as we are able to investigate the specific chemical mechanisms, largely without biotic interferences. The molecular mechanism of POM-mediated AgNP formation was analyzed using a novel combination of electron paramagnetic resonance (EPR), solid-state ${ }^{13} \mathrm{C}$ nuclear magnetic resonance (NMR), and fourier-transform infrared (FTIR) spectroscopy. The resulting mechanistic insights into the interactions between POM and Ag will improve our current understanding of the geochemistry of trace metals in soils.

\section{Results}

Reduction in sand matrix. The natural formation of AgNPs at soil surface was mimicked with a sand depth of $1 \mathrm{~mm}$ (light penetration in natural soils is $0.2-0.4 \mathrm{~mm})^{22}$ and exposure of the samples to natural sunlight irradiation for $10 \mathrm{~h}$ outdoors (Fig. 1a). In the presence of POM, the color of the supernatants was light brown (Fig. 1b). The formation of AgNPs was confirmed by the characteristic peak of surface plasmon resonance (SPR) at $\sim 400$ $\mathrm{nm}$ on ultraviolet (UV)-visible (Vis) spectrometry ${ }^{18}$ (Fig. 1c). A notable amount of AgNPs with diameters of $12.8 \pm 4.5 \mathrm{~nm}$ was observed in the liquid phase by transmission electron microscopy
(TEM) with energy dispersive X-ray spectrometry (EDS) (Fig. 1d, e). POM not only facilitated the formation of AgNPs in the presence of light, it also worked in the dark, as detected by liquid chromatography inductively coupled plasma mass spectrometry (LC-ICP-MS) (Fig. 1f). No AgNPs formed in the irradiated control without POM. These results indicated a significant role of POM in AgNPs formation at soil surface, despite the limited penetration of sunlight in the soil.

Reduction in simplified suspension. Experiments were then performed by incubating $9.3 \times 10^{-3}-0.93 \mathrm{mM} \mathrm{Ag}^{+}$with $\mathrm{POM}$ at 9.0-143.2 $\mathrm{mg} \mathrm{C} \mathrm{L}^{-1}$ under natural sunlight. After $24 \mathrm{~h}$, the suspensions were pale yellow (Supplementary Fig. 1) but only the suspension containing $0.93 \mathrm{mM} \mathrm{Ag}{ }^{+}$had an obvious SPR absorbance at $\sim 400 \mathrm{~nm}$ (Supplementary Fig. 2b). Further, the intensity of SPR at $\sim 400 \mathrm{~nm}$ increased with increasing POM concentrations (Supplementary Fig. 2b).

To further explore the operative conditions favoring $\mathrm{Ag}^{+}$reduction, $0.93 \mathrm{mM} \mathrm{Ag}{ }^{+}$was allowed to react with $143.2 \mathrm{mg} \mathrm{C} \mathrm{L}^{-1}$ POM under simulated sunlight over $\mathrm{pH}$ 5.6-8.6 at $25^{\circ} \mathrm{C}$ (Fig. 2a and Supplementary Fig. 3c). After $24 \mathrm{~h}$, all suspensions were yellow but only those under neutral and alkaline conditions (7.0-8.6) had obvious SPR absorbance at $\sim 400 \mathrm{~nm}$ (Supplementary Fig. 3c). This is attributed to the low dissolution of $\mathrm{AgNPs}^{23}$ and an increasing trend of radical signal intensity at higher $\mathrm{pHs}$ (as discussed later). Figure $2 \mathrm{~b}$ shows typical TEM images of nanoparticles at $\mathrm{pH} 8.6$, where notable amounts of nanoparticles with average diameters of $8.4 \pm 3.7$ and $7.7 \pm 3.8 \mathrm{~nm}$ were observed in liquid and particulate phase after 24 or $96 \mathrm{~h}$ incubation; the size was similar to that of samples from sand matrix (Fig. 1d). EDS confirmed the presence of $\mathrm{Ag}$ (Fig. 2b). On X-ray powder diffraction (XRD) analysis, the strong diffraction peak occurring at $38.2^{\circ}$ in the POM corresponded to metallic Ag facets of (111) (Fig. 2c). The species of Ag was further confirmed by X-ray photoelectron spectroscopy (XPS) analysis. The signals of $\mathrm{Ag} 3 \mathrm{~d}_{3 / 2}$ and $3 \mathrm{~d}_{5 / 2}$ were located at $373.9 \mathrm{eV}$ and $367.9 \mathrm{eV}$ (Fig. 2d), characteristic of metallic $\mathrm{Ag}^{24}$. AgNPs did not form in $\mathrm{Ag}^{+}$solution in the absence of POM (Supplementary Fig. 3a). Combined, the UV-Vis, TEM-EDS, XRD, and XPS results provides conclusive evidence of the formation of metallic AgNPs in the presence of POM under irradiation for $24 \mathrm{~h}$.

The possible role of DOM released from POM in reducing $\mathrm{Ag}^{+}$ to AgNPs was minimal based on the following evidence. Firstly, very little AgNPs formed when POM was replaced with its released DOM (Supplementary Fig. 4a, b). Secondly, the EPR signal of $\mathrm{O}_{2}^{--}$was not detected in the released DOM (Supplementary Fig. 4c, as described later). Finally, AgNPs were formed in a dialysis bag (pore size $<1 \mathrm{~nm}$, Spectrum, USA) containing POM but not in an incubation consisting of a bulk solution and released DOM (Supplementary Fig. 5). These observations suggest that, at least in our experimental system, POM serves as a natural insoluble agent for the reduction of $\mathrm{Ag}^{+}$to AgNPs under irradiation.

Reduction kinetics. In the heterogeneous system, only $\sim 15 \%$ of total AgNPs were distributed in liquid phase and the concentration was relatively constant after $85 \mathrm{~h}$ of incubation $(\sim 0.06 \mathrm{mM}$, Fig. 3a, and Supplementary Fig. 6a, c). By contrast, the amount of AgNPs in the particulate phase increased continuously (Fig. 3b and Supplementary Fig. 6b, d) and accounted for up to $\sim 85 \%$ of the total AgNPs formed (Fig. 3b).

The kinetics of AgNPs formation by POM were best described by the Finke-Watzky model that involves two pseudoelementary steps $^{25}$, by which $\mathrm{Ag}^{+}$was first reduced to zerovalent atoms (nuclei formation, $\left.\mathrm{Ag}^{+}+\mathrm{e}^{-} \stackrel{k_{1}}{\longrightarrow} \mathrm{Ag}^{0}\right)$ for their aggregation into nuclei 
a

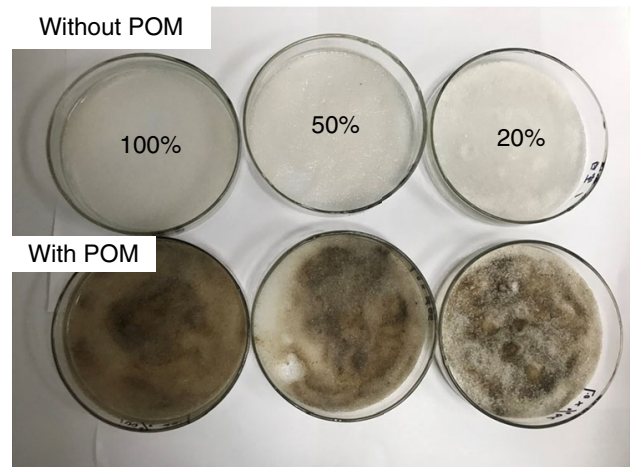

b
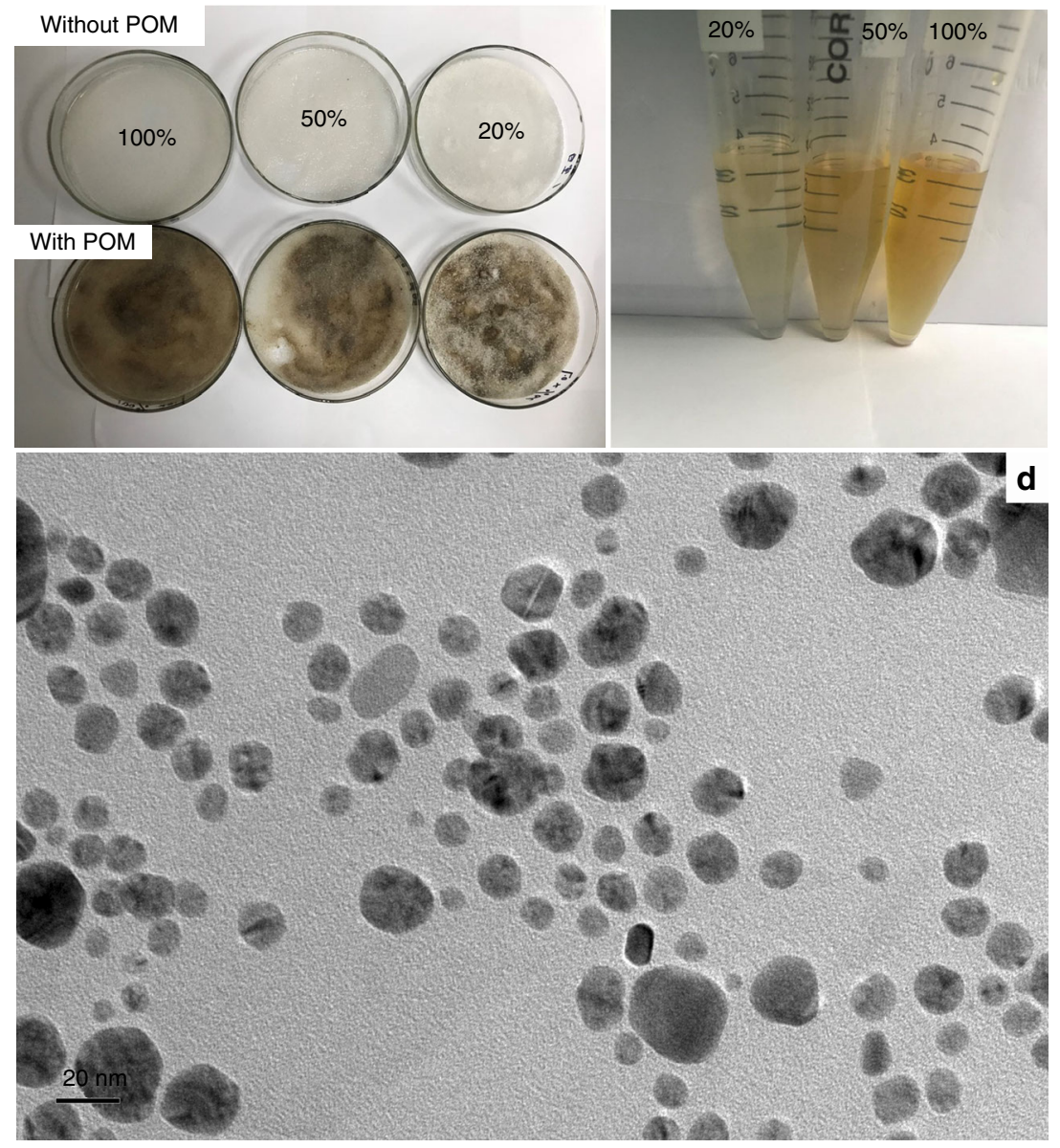

C

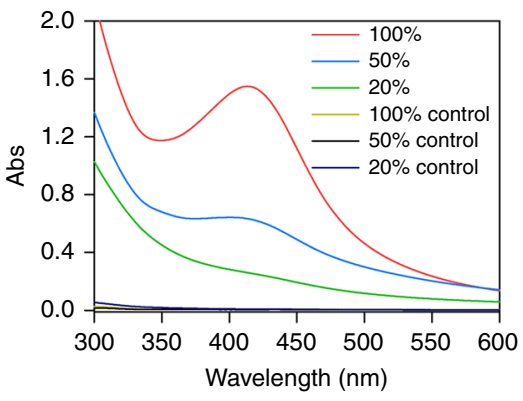

e
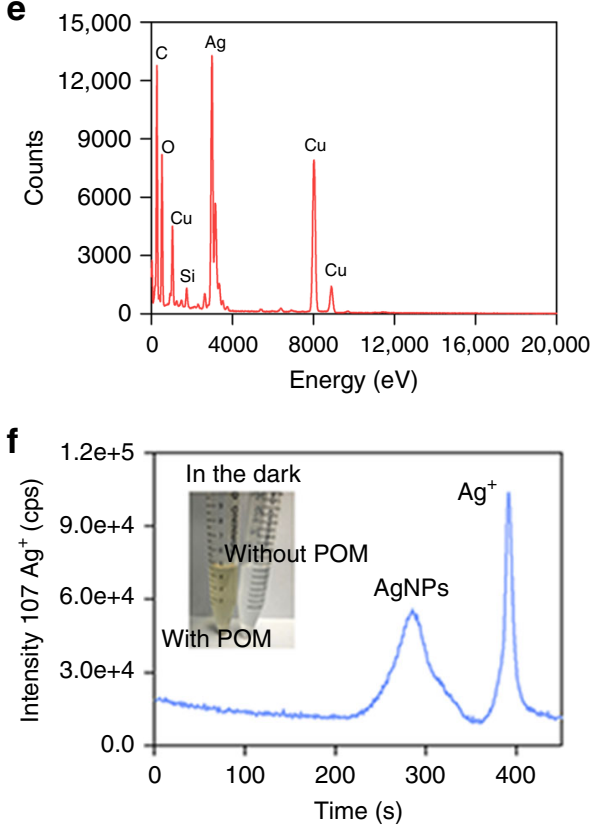

Fig. 1 Silver nanoparticles in sand matrix under natural irradiation. a Representative sand matrix samples without or with particulate organic matter (POM) at $20 \%, 50 \%$, and $100 \%$ humidity under natural irradiation for $10 \mathrm{~h}$ at $\sim 30^{\circ} \mathrm{C}$. b Color evolution of samples collected from the sand matrix in the presence of POM under conditions of different humidity. c Characteristic absorbance spectrum of AgNPs recorded by UV-Vis spectra in the supernatants. d TEM image of AgNPs formed in supernatants of samples with water-holding capacity of $100 \%$ in a. e EDS analysis of particles in d. $\mathbf{f}$ The formation of AgNPs after interaction of $\mathrm{Ag}^{+}$and POM in sand matrix in the dark as revealed by LC-ICP-MS

$\left(\operatorname{Ag}_{n}^{0}\right)$, followed by autocatalytic surface reduction enabled by the surface sites from just-formed nuclei of $\mathrm{Ag}_{n}^{0}$ (surface autocatalytic reduction, $\mathrm{Ag}_{n}^{0}+\mathrm{Ag}^{+}+\mathrm{e}^{-} \stackrel{k_{2}}{\longrightarrow} \mathrm{Ag}_{n+1}^{0}$ ). The autocatalytic reduction of salt precursor is also involved in the synthesis of other metal nanocrystals 26,27 . Therefore, the AgNPs formation could be expressed $\mathrm{as}^{25}$ :

$$
\begin{gathered}
\frac{\mathrm{d}\left[\mathrm{Ag}_{\mathrm{n}}^{0}\right]}{\mathrm{d} t}=-\frac{\mathrm{d}\left[\mathrm{Ag}^{+}\right]}{\mathrm{d} t}=k_{1}\left[\mathrm{Ag}^{+}\right]+k_{2}\left[\mathrm{Ag}^{+}\right]\left[\mathrm{Ag}_{n}^{0}\right] \\
{\left[\mathrm{Ag}_{n}^{0}\right]=\left[\mathrm{Ag}^{+}\right]_{0}-\left[\mathrm{Ag}^{+}\right]}
\end{gathered}
$$

where $\left[\mathrm{Ag}_{\mathrm{n}}^{0}\right]$ and $\left[\mathrm{Ag}^{+}\right]$are the concentrations of AgNPs and $\mathrm{Ag}^{+}$ in the heterogeneous system at time $t$, respectively; $\left[\mathrm{Ag}^{+}\right]_{o}$ is the concentrations of $\mathrm{Ag}^{+}$initially. The $k_{1}$ and $k_{2}$ are the rate constants for nuclei formation and surface autocatalytic reduction, respectively. $k_{1}$ and $k_{2}$ were derived from curve fitting according the Finke-Watzky model (Fig. 3d) ${ }^{25-27}$, and were $2.49 \times 10^{-3} \mathrm{~h}^{-1}$ and $4.47 \times 10^{-2} \mathrm{mM}^{-1} \mathrm{~h}^{-1}$, respectively. Thus, the nuclei formation was rate limiting $\left(k_{1} \ll k_{2}\right)$. The reduction rates of nuclei formation and autocatalysis surface reduction were further modeled as a function of reaction time (Supplementary Fig. 7). The autocatalytic reduction rate increased rapidly over time and after $\sim 7 \mathrm{~h}$ was higher than the rate of nuclei formation, suggesting that nuclei formation surpasses nuclei formation to become the dominant process. The rate constant $k_{1}$ for POM $\left(k_{1}=2.49 \times 10^{-3} \mathrm{~h}^{-1}\right)$ was roughly similar to that in DOM $\left(1 \times 10^{-3}-0.3 \mathrm{~h}^{-1}\right)^{20,28,29}$, suggesting that POM could reduce $\mathrm{Ag}^{+}$at comparable rates to DOM in lakes and rivers. However, the Finke-Watzky two-step mechanism of AgNPs formation by POM was not analogous to DOM with one-step mechanism ${ }^{20,28,29}$. A mechanistic understanding of the autocatalytic surface reduction was not the main focus of this study but merits further investigation. Note that the oxidation of AgNPs was not included in this model because oxidation was not favored under alkaline conditions, based on a reported pseudo-first-order rate constant of $9.58 \times 10^{-4} \mathrm{~h}^{-130}$.

POM induced superoxide reduction of $\mathbf{A g}^{+}$. The formation of AgNPs could be facilitated under irradiation, under highly alkaline conditions, or in the presence of dissolved $\mathrm{O}_{2}$ (Supplementary Fig. 3). The stimulated effect of dissolved $\mathrm{O}_{2}$ on AgNPs formation (Supplementary Fig. 3b) indicates that reactive oxygen species (ROS) are responsible for the observed reduction ${ }^{31}$. The ROS mediating AgNPs formation was identified as superoxide $\mathrm{O}_{2}^{--}$because the addition of superoxide dismutase (superoxide scavenger $)^{18}$ in the suspensions abolished AgNPs formation (Fig. 4a). This result is consistent with the suggested role of 
a
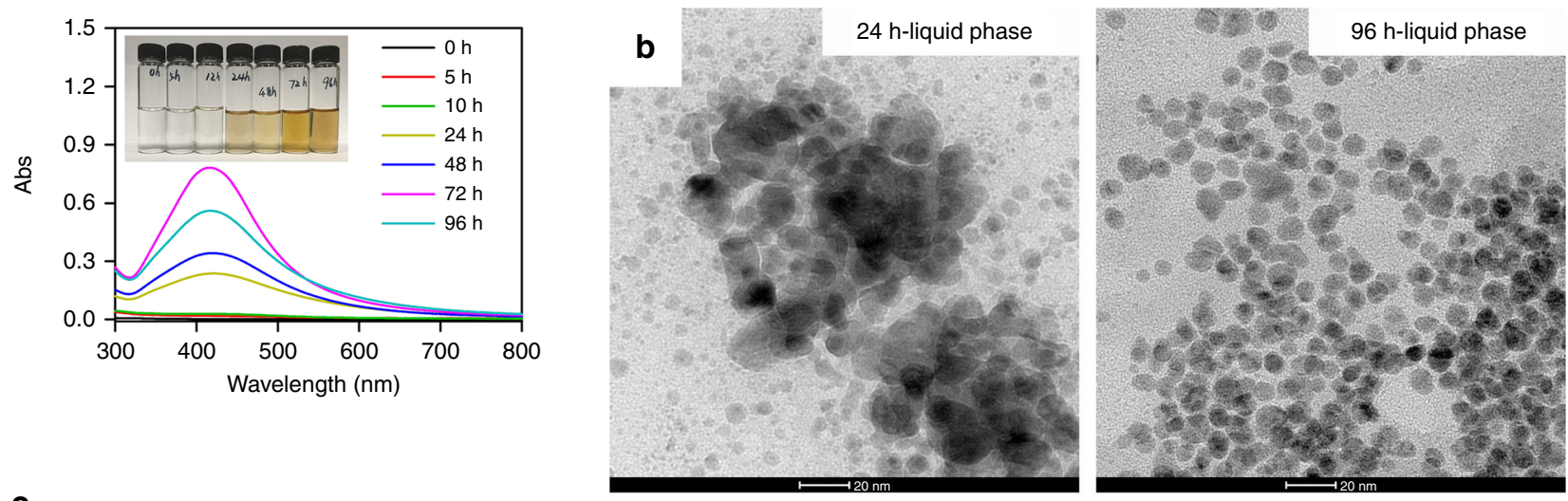

C
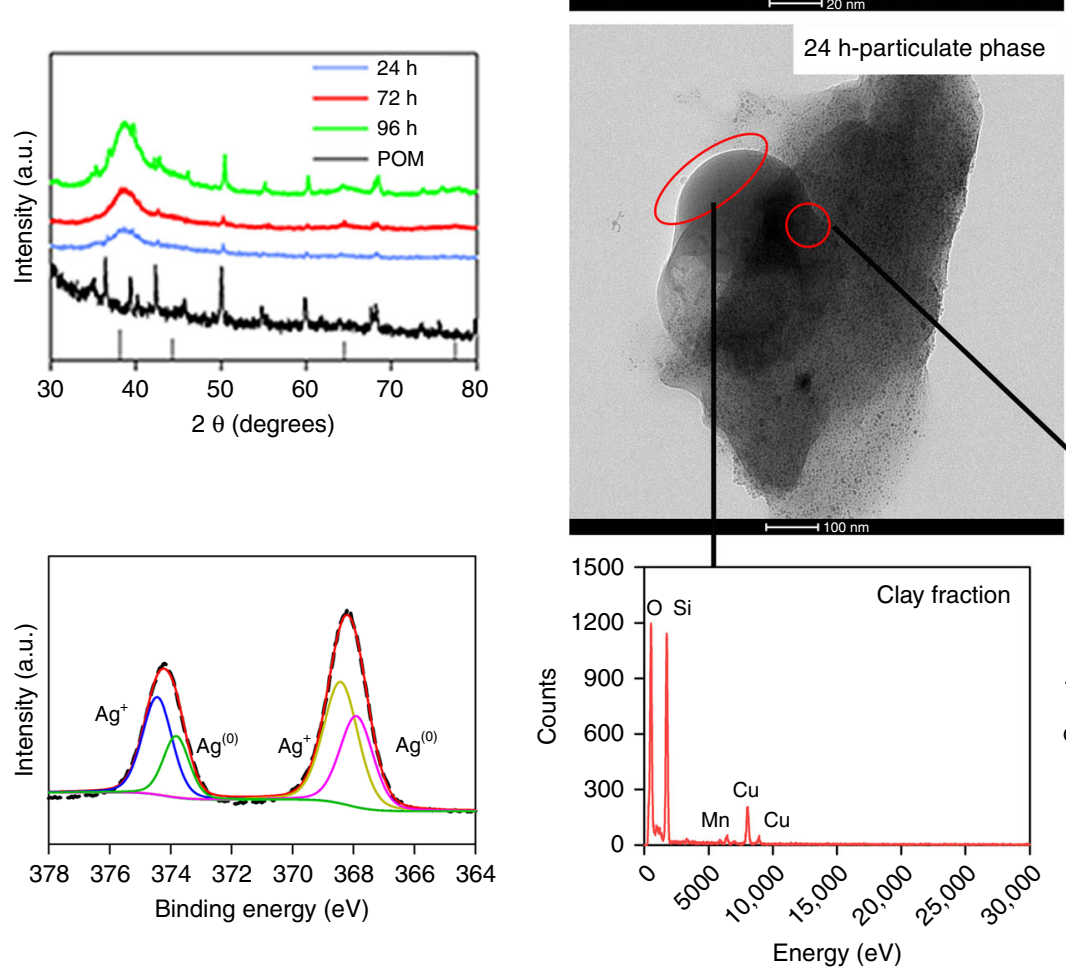

96 h-particulate phase

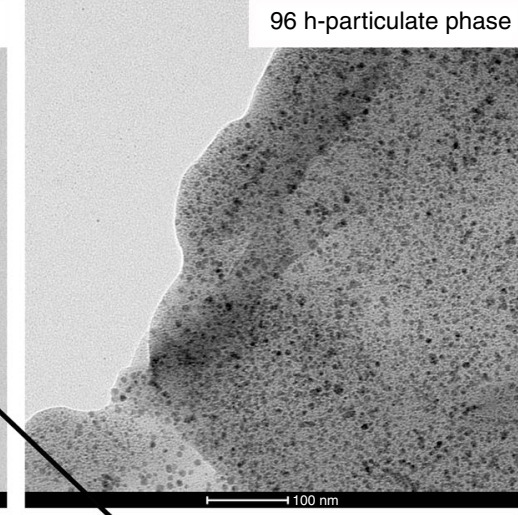

d
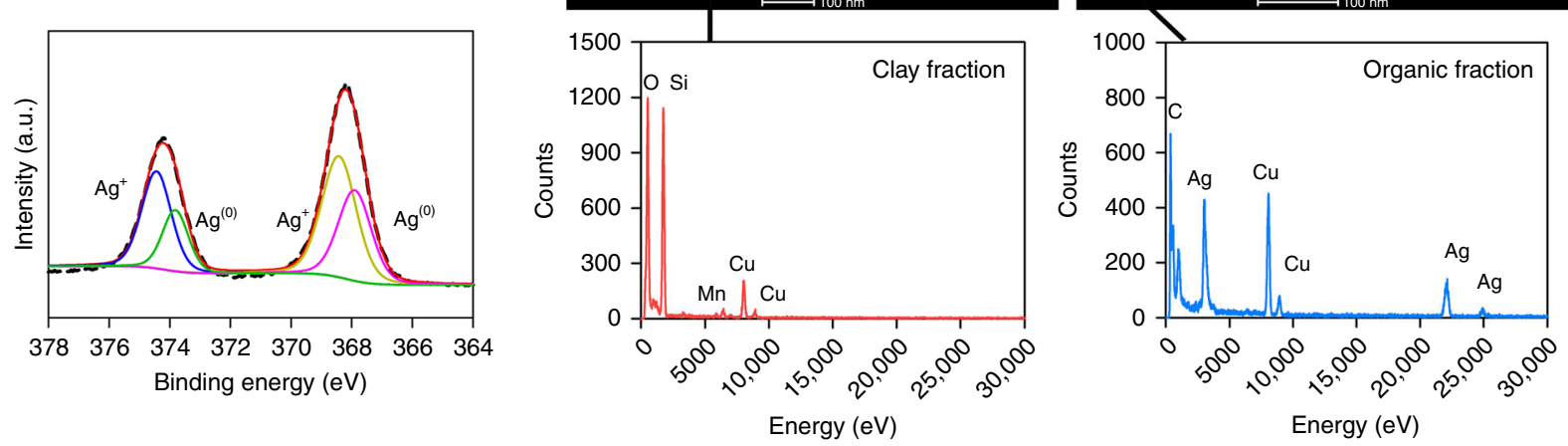

Fig. 2 Silver nanoparticles in simplified suspension under simulated sunlight. Silver ions $\left(\mathrm{Ag}^{+}\right)$at $0.93 \mathrm{mM}$ were incubated with particular organic matter $(P O M)$ at $143.2 \mathrm{mg} \mathrm{C} \mathrm{L}^{-1}$ at $\mathrm{pH}$ 8.6. a UV-Vis spectra of AgNPs in liquid phase (insert showing the color evolution of the sample over time). $\mathbf{b}$ TEM images of AgNPs in liquid and particulate phase and the respective EDS analysis after $24 \mathrm{~h}$ of incubation with POM. c XRD analysis of Ag loaded onto POM. $\mathbf{d}$ XPS analysis after the incubation of $\mathrm{Ag}^{+}$with POM for $24 \mathrm{~h}$

aquatic derived-DOM in promoting reduction of $\mathrm{Ag}^{+}$under illumination $^{18}$

EPR spectroscopy coupled with 5,5-dimethyl-1-pyrroline-Noxide (DMPO) as a spin-trapping agent confirmed the generation of superoxide. As illustrated in Fig. 4b, six characteristic peaks of the DMPO $-\mathrm{O}_{2}^{-}$spin adducts $^{32}$ were observed in the POM suspension under simulated sunlight irradiation over a $\mathrm{pH}$ range from 7.4 to 8.6. By contrast, the EPR signal of $\mathrm{O}_{2}^{--}$was not detected in the DOM released from POM (Supplementary Fig. 4c); the $\mathrm{O}_{2}^{--}$was thus not directly produced from DOM. Further, EPR spectra of POM in the absence of DMPO was corrected (Fig. 5a), and a single peak was observed with $g$ factor value of 2.0030. The $g$ factor value is characteristics of semiquinone radicals 33,34 , and thus suggests that semiquinone radicals are produced in the POM. It has been well established that semiquinone radicals produced from quinone-hydroquinone moieties can mediate the formation of $\mathrm{O}_{2}^{--}$via single-electron transfer process with oxygen ${ }^{35}$. Therefore, the electron-donating phenol-like groups of POM (e.g., hydroquinones) are likely responsible for $\mathrm{O}_{2}^{--}$generation. In contrast, no formation of AgNPs was observed in the reaction between ash and $\mathrm{Ag}^{+}$; intact and de-ashed POM showed comparable SPR absorbance intensity of AgNPs (Supplementary Fig. 4d). The radicals are thus not directly influenced by clays in POM.

${ }^{13} \mathrm{C}$ NMR and FTIR analyses were performed to further identify the organic moieties in POM that were responsible for $\mathrm{O}_{2}^{--}$production under illumination. The ${ }^{13} \mathrm{C}$ NMR spectrum confirmed the existence of phenolic moieties (Fig. $5 \mathrm{~b}$ and Supplementary Table 1). Furthermore, on the FTIR spectrum, the peak of pristine POM occurred at $\sim 3400 \mathrm{~cm}^{-1}$, which was attributed to the $\mathrm{O}-\mathrm{H}$ vibration of the carboxylic and alcoholic groups while the peak at $\sim 1600 \mathrm{~cm}^{-1}$ was assigned to aromatic $\mathrm{C}=\mathrm{C}$ or $\mathrm{C}=\mathrm{O}$ stretching and quinone $\mathrm{C}=\mathrm{O}^{36,37}$. The peaks at $\sim 2917 \mathrm{~cm}^{-1}$ and $1000 \mathrm{~cm}^{-1}$ were assigned to the $\mathrm{C}-\mathrm{H}$ stretching motions of aliphatic groups and the $\mathrm{C}-\mathrm{O}$ stretching of polysaccharide, respectively (Fig. 5c) ${ }^{36}$. Collectively, our data 

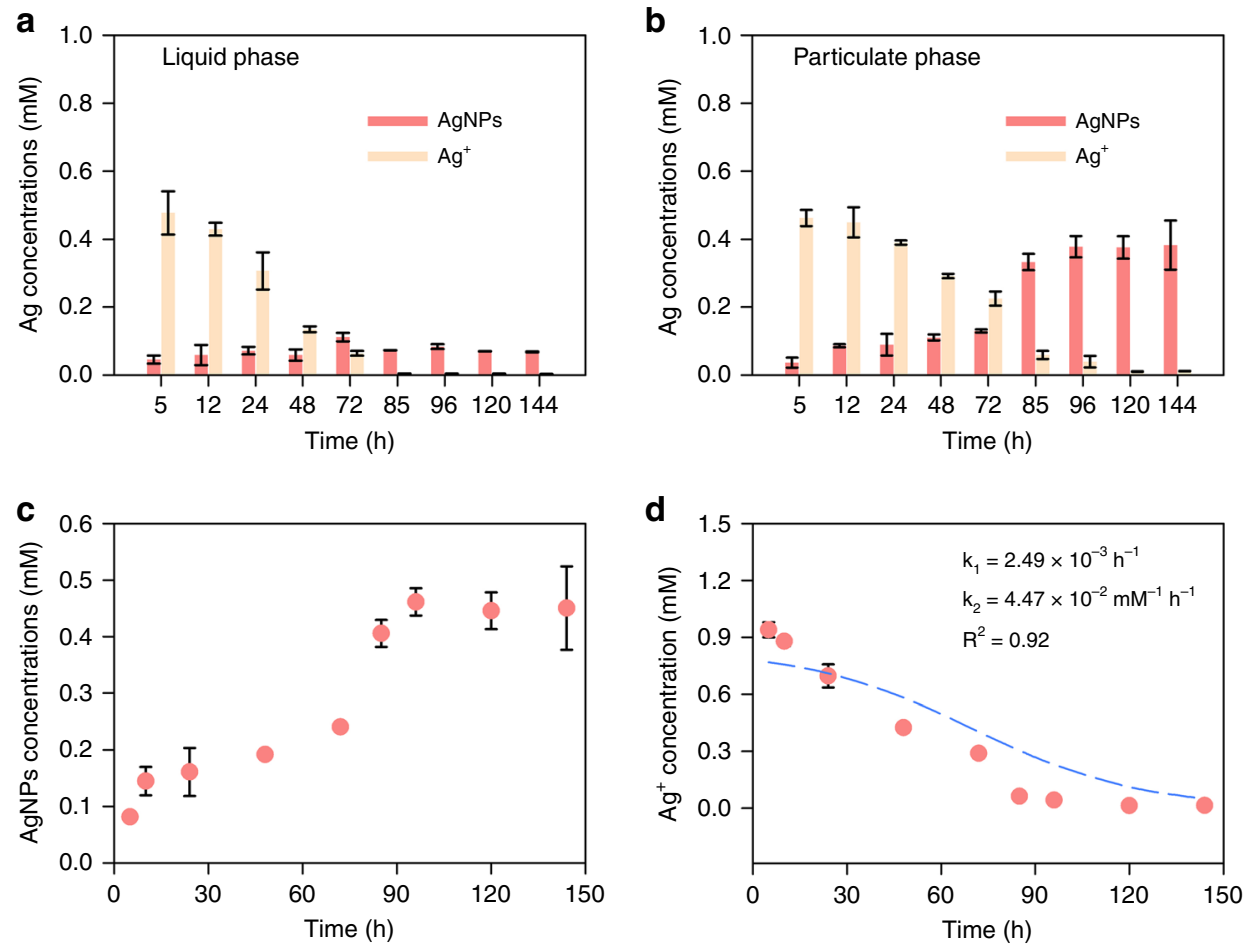

Fig. 3 Kinetics of silver nanoparticles formation. Silver ions $\left(\mathrm{Ag}^{+}\right)$at $0.93 \mathrm{mM}$ were incubated with particular organic matter (POM) at $143.2 \mathrm{mg} C \mathrm{~L}^{-1}$ under simulated sunlight at $\mathrm{pH}$ 8.6. The amount of $\mathrm{AgNPs}$ and $\mathrm{Ag}^{+}$in a liquid and $\mathbf{b}$ particulate phase. Total amount of $\mathbf{c} \mathrm{AgNPs}$ and $\mathbf{d} \mathrm{Ag}^{+}$in the heterogeneous system, and the experimental data were fitted using the Finke-Watzky model. Error bars represent the standard deviation of the mean of the triplicates
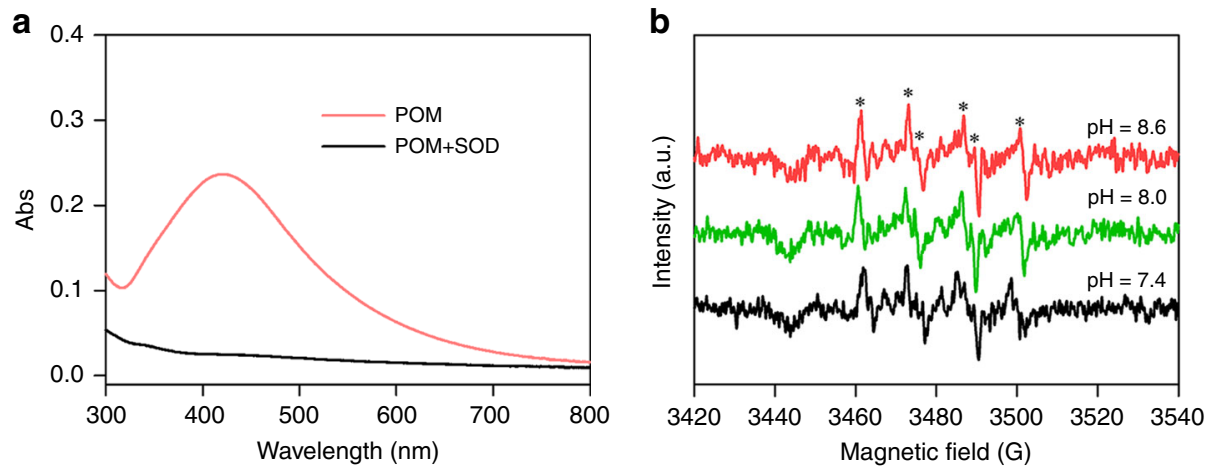

Fig. 4 Production of $\mathrm{O}_{2}^{--}$in particulate organic matter suspension. a A dramatic decrease in the SPR absorbance of the AgNPs suspension in the presence of $150 \mathrm{U}$ SOD mL ${ }^{-1}$, produced by the reduction of $0.93 \mathrm{mM}$ silver ions $\left(\mathrm{Ag}^{+}\right)$with $143.2 \mathrm{mg} \mathrm{CL}^{-1}$ particulate organic matter ( $\mathrm{POM}$ ) at $\mathrm{pH} 8.6$ under simulated sunlight for $24 \mathrm{~h}$. $\mathbf{b}$ EPR spectra of the DMPO adduct with $\mathrm{O}_{2}^{--}$in POM suspension at different pHs after incubation of the samples under simulated sunlight for $1 \mathrm{~h}$

points toward that phenol-like groups are important redox-active functional groups in POM, which could be excited under illumination, thus transferring electrons to dissolved $\mathrm{O}_{2}$ to form superoxide radicals ${ }^{37,38}$. Additionally, it is reported that the presence of particulates could increase the reactivity of superoxides $^{39}$, which may explain why more AgNPs formed in particulates relative to liquid phase (Fig. $3 a, b)$. The role of particulates in soil matrix in formation/decaying of superoxide awaits further investigation.

\section{Discussion}

Our hypothesis that POM is redox active is supported by all our experimental results. POM reduces $\mathrm{Ag}^{+}$to AgNPs under irradiation and in the dark, suggesting the photoreduction and non-photoreduction pathway. EPR, ${ }^{13} \mathrm{C}$ NMR, and FTIR analyses reveal that phenol-like groups are involved in the redox activity of POM (Fig. 5). The redox potentials of these groups 40,41 and $\mathrm{POM}^{7,36}$ are documented to range from -0.49 to $0.37 \mathrm{~V}$ (versus a standard hydrogen electrode) and for $\mathrm{Ag}^{+}$is $0.8 \mathrm{~V}$ (versus a standard hydrogen electrode $)^{42}$. These result in negative reaction free energies, ranging from -124.5 to $-41.5 \mathrm{~kJ} \mathrm{~mol}^{-1}$. Reduction of $\mathrm{Ag}^{+}$by POM is, thus, thermodynamically favorable. The photoreduction pathway was predominately mediated by $\mathrm{O}_{2}^{--}$, as evidenced by the EPR signal of $\mathrm{O}_{2}^{--}$(Fig. 4b). The nonphotoreduction pathway could be attributed to direct electron transfer from phenol-like groups within $\mathrm{POM}$ to $\mathrm{Ag}^{+}$. However, there was insufficient amounts of AgNPs in the dark, as reflected 

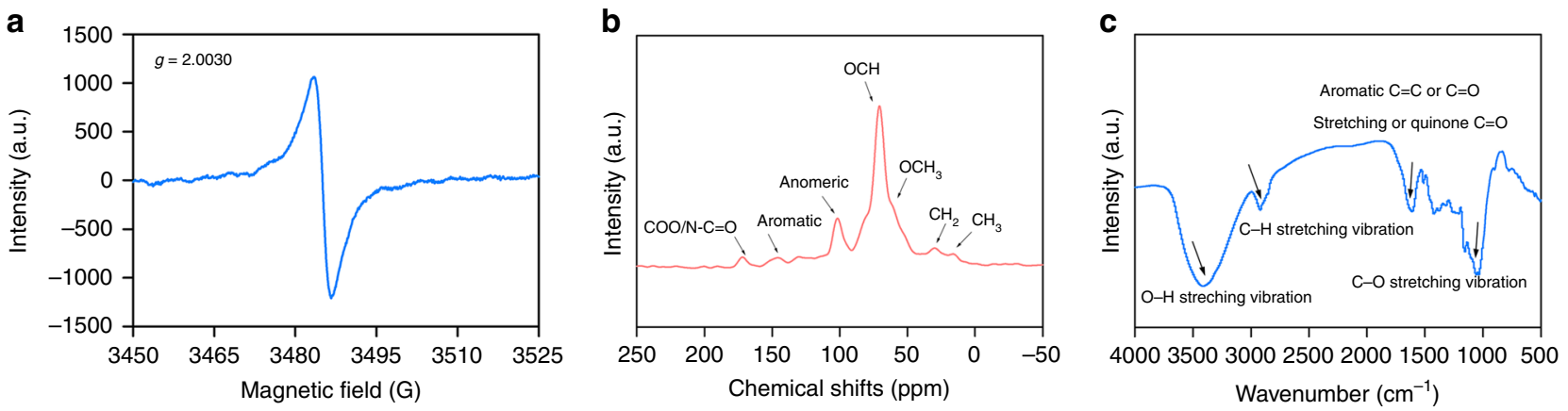

Fig. 5 Characteristics of particular organic matter. a EPR spectrum. b ${ }^{13} \mathrm{C}$ NMR spectrum. c FTIR spectrum

by little or no change in the SPR absorbance at $\sim 400 \mathrm{~nm}$ by $\mathrm{UV}-\mathrm{V}$ is spectrometry (Supplementary Fig. 2a) or diffraction peaks representative of metallic Ag by XRD (Supplementary Fig. 2c).

There are two possible mechanisms of natural AgNPs formation at soil surface: abiotic reduction via POM as shown in this study and biotic reduction (e.g., microbacteria and their associated extracellular polymer substances) ${ }^{14,43}$. The relative importance of these sources to AgNPs formation in soils has not yet been quantified. Typically, Ag concentrations in soils ranges from 0.01 to $126.0 \mathrm{mg} \mathrm{kg}^{-1}\left(9.3 \times 10^{-5}-1.2 \mathrm{mM}\right)^{10,44}$. Based on an extrapolation of our results to these environmental relevant concentrations, we estimate that between $1.2 \times 10^{-3}$ and $53.0 \mathrm{mg} \mathrm{AgNPs} \mathrm{kg}^{-1}$ would be formed from abiotic reduction via POM at equilibrium (based on $k_{1}=2.49 \times$ $10^{-3} \mathrm{~h}^{-1}$ and $\left.k_{2}=4.47 \times 10^{-2} \mathrm{mM}^{-1} \mathrm{~h}^{-1}\right)$. In contrast, the biotic reduction rate of AgNPs is $0.056 \mathrm{~h}^{-1}$ (ref. ${ }^{29}$ ), which should yield from $9.3 \times 10^{-3}$ to $117.4 \mathrm{mg} \mathrm{AgNPs} \mathrm{kg}{ }^{-1}$ (obtained from pseudo-first-order kinetic) ${ }^{29}$. Thus, $11-31 \%$ of the AgNPs in the soil surface may originate from POM, as compared to $69-89 \%$ of biotic reduction. This may reflect high AgNP concentrations in POM-rich soils or sediments. This study clearly demonstrates that POM can contribute significantly to the natural formation of AgNPs in soils.

Taken together, our results introduce a new pathway for AgNPs formation in soils, whereby $\mathrm{O}_{2}^{--}$, generated from phenol-like groups within POM under irradiation, is a key determinant of $\mathrm{Ag}^{+}$reduction. Even in the dark, POM is redox active in AgNPs formation. Consequently, these results highlight the importance but unrecognized role of POM in naturally occurring AgNPs in soils. Given POM is associated with iron oxides, clays and DOM in natural soils and sediments ${ }^{3-5}$, the formation of AgNPs could be more complex in nature. This reductive pathway will ultimately raise the concerns of POM in the biogeochemistry of contaminants that are reactive towards phenol-like groups.

\section{Methods}

Extraction and characterization of POM. POM was extracted from a peat soil with $34.1 \%$ organic carbon from Changbai Mountain, China $\left(42^{\circ} 9^{\prime} 51^{\prime \prime} \mathrm{N}, 126^{\circ} 44^{\prime} 7^{\prime \prime}\right.$ E). Briefly, the air-dried and sieved soil $(0.2 \mathrm{~mm})$ was progressively extracted with $0.1 \mathrm{M} \mathrm{Na}_{4} \mathrm{P}_{2} \mathrm{O}_{7}$ eight times, $0.1 \mathrm{M} \mathrm{NaOH} 20$ times, and then $0.2 \mathrm{M} \mathrm{NaOH}$ ten times with an extractant/soil ratio of 10:1, followed by centrifugation at $4500 \times g$ for 20 min. The samples were then washed with Milli-Q water, freeze-dried, ground until they were fine enough to pass through a 100 -mesh $(0.15 \mathrm{~mm}) \operatorname{sieve}^{45}$ and used in the analyses described below.

The carbon, hydrogen, nitrogen, and oxygen contents of the POM were determined using a Vario EL III element analyzer (Germany) (Supplementary Table 1). The ash content was determined by heating the POM sample at $800^{\circ} \mathrm{C}$ for $4 \mathrm{~h}$ and calculated based on the mass difference (Supplementary Table 1$)^{46}$. Subsamples were de-ashed in $1.6 \mathrm{M} \mathrm{HCl}$ and $3 \mathrm{M} \mathrm{HF}$ at extractant/soil ratio of 10:1 for $24 \mathrm{~h}$ seven times (designated as de-ashed POM). DOM released from the POM suspension was monitored over $96 \mathrm{~h}$ using a total organic carbon analyzer (Multi N/C 3100, Analytik, Jena, Germany).

Reduction in sand matrix. The experiment was performed to mimic the possible natural formation of AgNPs in the presence of POM on the soil surface. Commercial quartz sand with a grain size of $0.3-0.7 \mathrm{~mm}$ was thoroughly cleaned with $0.01 \mathrm{M} \mathrm{HNO}_{3}$ and $\mathrm{NaOH}^{47}$. A uniform layer of $1 \mathrm{~mm}$ sand was formed in glass Petri dishes ( $9 \mathrm{~cm}$ in diameter) using $14 \mathrm{~g}$ of quartz sand, with or without $0.3 \mathrm{~g}$ of POM, corresponding to POM content in natural soil ${ }^{48}$. Each experimental group was spiked with $\mathrm{Ag}^{+}$(as $\mathrm{AgNO}_{3}, \mathrm{pH} 8.6$ ) at $100 \mathrm{mg} \mathrm{kg}^{-1}$ (dry weight), rewetted periodically to maintain a water-holding capacity of 20,50 , and $100 \%$, covered with polyvinyl chloride film, and irradiated for $10 \mathrm{~h}$ outdoors under natural sunlight [6,820-178,900 lux, measured using a digital lux meter (BENETECH GM1010, China)]. After $10 \mathrm{~h}$, the resulting AgNPs were analyzed. The experiments were also conducted in the dark.

Reduction in simplified suspension. Silver nitrate $\left(\mathrm{AgNO}_{3}\right)$ at $9.3 \times 10^{-3}-0.93$ $\mathrm{mM}$ was allowed to react with POM at $9.0-143.2 \mathrm{mg} \mathrm{C} \mathrm{L}^{-1}$ at $\mathrm{pH} 5.6-8.6$. Modeling calculations confirmed that under all $\mathrm{pH}$ conditions $>99.9 \%$ of the $\mathrm{Ag}$ was present as $\mathrm{Ag}^{+}$(Visual MINTEQ 3.1). The suspensions were rotated at 500 $\mathrm{rpm}$ at $25^{\circ} \mathrm{C}$ to ensure uniform light exposure and a well-mixed suspension ${ }^{37}$ in a photo-chemical reactor equipped with a water-circulating jacket for temperature control (XPA-7, Nanjing Xujiang Electromechanical Plant, China). The simulated sunlight was provided by a xenon source lamp $(250-1100 \mathrm{~nm})$ without light filters at $500 \mathrm{~W} / \mathrm{m}^{2}$. AgNPs production was also evaluated under natural sunlight as well as in the dark (covered with aluminum foil). A parallel experiment was performed to study the effect of $\mathrm{O}_{2}$ on $\mathrm{Ag}^{+}$reduction in which the suspension was purged with high-purity $\mathrm{N}_{2}$ for at least $30 \mathrm{~min}$ before exposure to simulated sunlight. SOD $\left(150 \mathrm{U} \mathrm{mL}^{-1}\right)$ was added to the suspension to determine the role of $\mathrm{O}_{2}^{--}$. All experiments were conducted with at least duplicate samples.

Characterization of AgNPs. At each time point, the suspensions were immediately filtered through a $0.45-\mu \mathrm{m}$ filter and the resulting AgNPs in liquid phase were tracked by UV-Vis spectrophotometry at $300-800 \mathrm{~nm}$. After rinsing with Milli-Q water, the POM was freeze-dried for X-ray Powder Diffraction (XRD, Ultima IV, Rigaku, Japan) and X-ray Photoelectron Spectrometer (XPS, ESCALAB 2500Xi, Thermo, USA) analyses. Transmission electron microscopy (TEM) with energy dispersive X-ray spectrometry (EDS) (JEM200CX, Japan) was performed at an accelerating voltage of $200 \mathrm{kV}$. NPs size was obtained using Nano Measure System 1.2.0 to analysis TEM images of at least 300 particles. Liquid chromatography inductively coupled plasma mass spectrometry (LC-ICP-MS) was also applied in the work to characterize the AgNPs at low concentrations ${ }^{49}$. Ultrafiltration coupled with inductively coupled plasma mass spectrometry (ICP-MS, Thermo-iCAP Q, USA) was used to quantitate $\mathrm{Ag}^{+}$and AgNPs in liquid and particulate phase. The $\mathrm{Ag}^{+}$in the liquid phase was measured by a $3-\mathrm{kDa}$ centrifugal ultrafilter (Amicon Ultra-15 $3 \mathrm{kDa}$, Millipore $)^{50,51}$; the resulting AgNPs were then quantified by subtracting the $\mathrm{Ag}^{+}$concentration from the total Ag concentration. The AgNPs on POM were extracted with $3 \mathrm{~mL}$ of $2.5 \mathrm{mM}$ tetrasodium pyrophosphate (TSPP $)^{52}$. The AgNPs were then quantified as described for the liquid phase. The results are presented as mean \pm s.d. based on the results of $n=3$ samples.

FTIR, solid-state ${ }^{13} \mathbf{C}$ NMR, and EPR analyses. To identify the structural components in POM responsible for $\mathrm{Ag}^{+}$reduction, FTIR spectrometry (Nicolet iS10, Thermo, USA), solid-state ${ }^{13} \mathrm{C}$ NMR (Burker Avance IIIHD $400 \mathrm{WB}$ ), and electron paramagnetic resonance spectrometry (EPR, EMX 10/12, Bruker, Germany) with a resonance frequency of $9.77 \mathrm{GHz}$ of POM were performed ${ }^{53}$. The dimethyl sulfoxide (DMSO) and 5,5-dimethyl-1-pyrroline-N-oxide (DMPO, J\&K Scientific Ltd, Shanghai, China) at $100 \mathrm{mM}$ was used to trap the $\mathrm{O}_{2}^{--}$and generate the EPR signals (DMPO-O ${ }_{2}^{--}$) in the POM recorded in EPR spectra. A parallel experiment was also 
conducted using a DOM solution, released from POM, to rule out its potential effect on $\mathrm{O}_{2}^{-}$generation.

\section{Data availability}

The authors declare that the data supporting the findings of this study are available within the paper and its Supplementary Information files.

Received: 25 January 2019 Accepted: 10 July 2019

Published online: 21 August 2019

\section{References}

1. Lehmann, J. \& Kleber, M. The contentious nature of soil organic matter. Nature 528, 60-68 (2015).

2. Scharlemann, J. P. W., Tanner, E. V. J., Hiederer, R. \& Kapos, V. Global soil carbon: understanding and managing the largest terrestrial carbon pool. Carbon Manag. 5, 81-91 (2014).

3. Stevenson, F. J. Humus Chemistry: Genesis, Composition, Reactions (John Wiley, New York, 1994).

4. Rice, J. A. Humin. Soil Sci. 166, 848-857 (2001).

5. Hayes, M. H. B., Mylotte, R. \& Swift, R. S. Humin: its composition and importance in soil organic matter. Adv. Agron. 143, 47-138 (2017).

6. Roden, E. E. et al. Extracellular electron transfer through microbial reduction of solid-phase humic substances. Nat. Geosci. 3, 417-421 (2010).

7. Zhang, C. F. \& Katayama, A. Humin as an electron mediator for microbial reductive dehalogenation. Environ. Sci. Technol. 46, 6575-6583 (2012).

8. Lau, M. P., Sander, M., Gelbrecht, J. \& Hupfer, M. Solid phases as important electron acceptors in freshwater organic sediments. Biogeochemistry 123, 49-61 (2015).

9. Alvarez, P. J. J., Chan, C. K., Elimelech, M., Halas, N. J. \& Villagan, D. Emerging opportunities for nanotechnology to enhance water security. Nat. Nanotechnol. 13, 634-641 (2018).

10. Hooda, P. S. Trace Elements in Soils. (John Wiley, New York, 2010).

11. Sekine, R. et al. Speciation and lability of Ag-, $\mathrm{AgCl}-$, and $\mathrm{Ag}_{2} \mathrm{~S}$-nanoparticles in soil determined by X-ray absorption spectroscopy and diffusive gradients in thin films. Environ. Sci. Technol. 49, 897-905 (2015).

12. Settimio, L. et al. Fate and lability of silver in soils: effect of ageing. Environ. Pollut. 191, 151-157 (2014).

13. Li, M., Wang, P., Dang, F. \& Zhou, D. M. The transformation and fate of silver nanoparticles in paddy soil: effects of soil organic matter and redox conditions. Environ. Sci: Nano 4, 919-928 (2017).

14. Kang, F. X., Alvarez, P. J. \& Zhu, D. Q. Microbial extracellular polymeric substances reduce $\mathrm{Ag}^{+}$to silver nanoparticles and antagonize bactericidal activity. Environ. Sci. Technol. 48, 316-322 (2014).

15. Klaus, T., Joerger, R., Olsson, E. \& Granqvist, C. G. Silver-based crystalline nanoparticles, microbially fabricated. Proc Natl Acad. Sci. USA 96, 13611-13614 (1999).

16. Yin, Y. G. et al. Superoxide-mediated extracellular biosynthesis of silver nanoparticles by the fungus fusarium oxysporum. Environ. Sci. Technol. Lett. 3, 160-165 (2016).

17. Adegboyega, N. F. et al. Interactions of aqueous $\mathrm{Ag}^{+}$with fulvic acids: mechanisms of silver nanoparticle formation and investigation of stability. Environ. Sci. Technol. 47, 757-764 (2013).

18. Yin, Y. G., Liu, J. F. \& Jiang, G. B. Sunlight-induced reduction of ionic Ag and Au to metallic nanoparticles by dissolved organic matter. ACS Nano 6, 7910-7919 (2012).

19. Akaighe, N. et al. Humic acid-induced silver nanoparticle formation under environmentally relevant conditions. Environ. Sci. Technol. 45, 3895-3901 (2011).

20. Hou, W. C., Stuart, B., Howes, R. \& Zepp, R. G. Sunlight-driven reduction of silver ions by natural organic matter: formation and transformation of silver nanoparticles. Environ. Sci. Technol. 47, 7713-7721 (2013).

21. Kang, S. H., Amarasiriwardena, D., Veneman, P. \& Xing, B. S. Characterization of ten sequentially extracted humic acids and a humin from a soil in western Massachusetts. Soil Sci. 168, 880-887 (2003).

22. Hebert, V. R. \& Miller, G. C. Depth dependence of direct and indirect photolysis on soil surfaces. J. Agr. Food Chem. 38, 913-918 (1990).

23. Yu, S., Yin, Y., Zhou, X., Dong, L. \& Liu, J. Transformation kinetics of silver nanoparticles and silver ions in aquatic environments revealed by double stable isotope labeling. Environ. Sci.: Nano 3, 883-893 (2016).

24. Yao, Y., Gao, B., Wu, F., Zhang, C. \& Yang, L. Engineered biochar from biofuel residue: characterization and its silver removal potential. ACS Appl. Mater. Interfaces 7, 10634-10640 (2015).

25. Watzky, M. A. \& Finke, R. G. Nanocluster size-control and "magic number" investigations. experimental tests of the "living-metal polymer" concept and of mechanism-based size-control predictions leading to the syntheses of Iridium (0) nanoclusters centering about four sequential magic numbers. Chem. Mater. 9, 3083-3095 (1997).

26. Harada, M. \& Kizaki, S. Formation mechanism of gold nanoparticles synthesized by photoreduction in aqueous ethanol solutions of polymers using in situ quick scanning X-ray absorption fine structure and small-angle X-ray scattering. Cryst. Growth Des. 16, 1200-1212 (2016).

27. Yang, T. H. et al. Toward a quantitative understanding of the reduction pathways of a salt precursor in the synthesis of metal nanocrystals. Nano Lett. 17, 334-340 (2017)

28. Yin, Y. G. et al. Photoreduction and stabilization capability of molecular weight fractionated natural organic matter in transformation of silver ion to metallic nanoparticle. Environ. Sci. Technol. 48, 9366-9373 (2014).

29. Zhang, X., Yang, C. W., Yu, H. Q. \& Sheng, G. P. Light-induced reduction of silver ions to silver nanoparticles in aquatic environments by microbial extracellular polymeric substances (EPS). Water Res. 106, 242-248 (2016).

30. Liu, J. \& Hurt, R. H. Ion release kinetics and particle persistence in aqueous nano-silver colloids. Environ. Sci. Technol. 44, 2169-2175 (2010).

31. He, D., Garg, S. \& Waite, T. D. $\mathrm{H}_{2} \mathrm{O}_{2}$-mediated oxidation of zero-valent silver and resultant interactions among silver nanoparticles, silver ions, and reactive oxygen species. Langmuir 28, 10266-10275 (2012).

32. Li, Y. et al. Effects of chloride ions on dissolution, ROS generation, and toxicity of silver nanoparticles under UV irradiation. Environ. Sci. Technol. 52, 4842-4849 (2017)

33. Sealy, R. C., Felix, C. C., Hyde, J. S. \& Swartz, H. M. in Free Radicals in Biology (ed. Pryor, W. A.), 209-259 (Academic Press, New York, 1980).

34. Squadrito, G. L., Cueto, R., Dellinger, B. \& Pryor, W. A. Quinoid redox cycling as a mechanism for sustained free radical generation by inhaled airborne particulate matter. Free Radic. Biol. Med. 31, 1132-1138 (2001).

35. Zafiriou, O. C., Joussot-Dubien, J., Zepp, R. G. \& Zika, R. G. Photochemistry of natural waters. Environ. Sci. Technol. 18, 358-371 (1984).

36. Zhang, C. F. et al. Characterization of humins from different natural sources and the effect on microbial reductive dechlorination of pentachlorophenol. Chemosphere 131, 110-116 (2015)

37. Fang, G. D., Liu, C., Wang, Y. J., Dionysiou, D. D. \& Zhou, D. M Photogeneration of reactive oxygen species from biochar suspension for diethyl phthalate degradation. Appl. Catal. B-Environ. 214, 34-45 (2017).

38. Li, Y., Niu, J. F., Shang, E. X. \& Crittenden, J. C. Synergistic photogeneration of reactive oxygen species by dissolved organic matter and $\mathrm{C}_{60}$ in aqueous phase. Environ. Sci. Technol. 49, 965-973 (2015).

39. Furman, O. Reactivity of oxygen species in homogeneous and heterogeneous aqueous environments. Diss. Theses-Gradworks 25, 3823-3826 (2009).

40. Klupfel, L., Piepenbrock, A., Kappler, A. \& Sander, M. Humic substances as fully regenerable electron acceptors in recurrently anoxic environments. Nat. Geosci. 7, 195-200 (2014).

41. Aeschbacher, M., Sander, M. \& Schwarzenbach, R. P. Novel electrochemical approach to assess the redox properties of humic substances. Environ. Sci. Technol. 44, 87-93 (2010)

42. Cotton, S. A. Chemistry of Precious Metals, Blackie Academic \& Professional (Springer, London, 1997).

43. Sharma, V. K., Yngard, R. A. \& Lin, Y. Silver nanoparticles: green synthesis and their antimicrobial activities. Adv. Colloid Interface Sci. 145 83-96 (2009)

44. Asami, T., Saeki, S., Goto, H., Nakazawa, M. \& Kubota, M. Silver Contamination of the soils and sediments near mines and/or smelters. Jpn. J. Soil Sci. Plant Nutr. 71, 179-186 (2000).

45. Wen, B. et al. Phenanthrene sorption to soil humic acid and different humin fractions. Environ. Sci. Technol. 41, 3165-3171 (2007)

46. Yang, Y., Shu, L., Wang, X., Xing, B. S. \& Tao, S. Impact of de-ashing humic Acid and humin on organic matter structural properties and sorption mechanisms of phenanthrene. Environ. Sci. Technol. 45, 3996-4002 (2011).

47. He, J. Z., Li, C. C., Wang, D. J. \& Zhou, D. M. Biofilms and extracellular polymeric substances mediate the transport of graphene oxide nanoparticles in saturated porous media. J. Hazard. Mater. 300, 467-474 (2015).

48. Bogan, B. W. \& Trbovic, V. Effect of sequestration on PAH degradability with Fenton's reagent: roles of total organic carbon, humin, and soil porosity. J. Hazard. Mater. 100, 285-300 (2003).

49. Zhou, X. X., Liu, R. \& Liu, J. F. Rapid chromatographic separation of dissoluble $\operatorname{Ag}(\mathrm{I})$ and silver-containing nanoparticles of 1-100 nanometer in antibacterial products and environmental waters. Environ. Sci. Technol. 48, 14516-14524 (2014).

50. Li, M., Dang, F., Fu, Q. L., Zhou, D. M. \& Yin, B. Effects of molecular weightfractionated natural organic matter on the phytoavailability of silver nanoparticles. Environ. Sci: Nano 5, 969-979 (2018).

51. Dang, F. et al. Discerning the sources of silver nanoparticle in a terrestrial food chain by stable isotope tracer technique. Environ. Sci. Technol. 53, 3802-3810 (2019). 
52. Schwertfeger, D. M. et al. Extracting metallic nanoparticles from soils for quantitative analysis: method development using engineered silver nanoparticles and SP-ICP-MS. Anal. Chem. 89, 2505-2513 (2017).

53. Xu, J., Zhao, B., Chu, W., Mao, J. \& Zhang, J. Chemical nature of humic substances in two typical Chinese soils (upland vs paddy soil): a comparative advanced solid state NMR study. Sci. Total Environ. 576, 444-452 (2017).

\section{Acknowledgements}

Financial supports were provided by the National Natural Science Foundation of China (41430752, 41501247 and 41771526) and the Natural Science Foundation of Jiangsu Province (BK20131041).

\section{Author contributions}

F.D., Y.N.H. and T.T.Q. designed the study; Experiments were conducted by Y.N.H. and M.L. The manuscript was prepared by Y.N.H. and F.D. with contributions from T.T.Q., Y.G.Y. and D.M.Z.

\section{Additional information}

Supplementary Information accompanies this paper at https://doi.org/10.1038/s41467019-11643-6.

Competing interests: The authors declare no competing interests.
Reprints and permission information is available online at http://npg.nature.com/ reprintsandpermissions/

Peer review information: Nature Communications thanks anonymous reviewer(s) for their contribution to the peer review of this work. Peer reviewer reports are available.

Publisher's note: Springer Nature remains neutral with regard to jurisdictional claims in published maps and institutional affiliations.

\section{(c) (i)}

Open Access This article is licensed under a Creative Commons Attribution 4.0 International License, which permits use, sharing, adaptation, distribution and reproduction in any medium or format, as long as you give appropriate credit to the original author(s) and the source, provide a link to the Creative Commons license, and indicate if changes were made. The images or other third party material in this article are included in the article's Creative Commons license, unless indicated otherwise in a credit line to the material. If material is not included in the article's Creative Commons license and your intended use is not permitted by statutory regulation or exceeds the permitted use, you will need to obtain permission directly from the copyright holder. To view a copy of this license, visit http://creativecommons.org/licenses/by/4.0/.

(C) The Author(s) 2019 